\title{
Correction to: Is There an Association Between Diet, Physical Activity and Depressive Symptoms in the Perinatal Period? An Analysis of the UPBEAT Cohort of Obese Pregnant Women
}

\author{
Claire A. Wilson ${ }^{1}(1) \cdot$ Paul Seed $^{2} \cdot$ Angela C. Flynn $^{2} \cdot$ Louise M. Howard $^{1} \cdot$ Emma Molyneaux $^{1} \cdot$ Julie Sigurdardottir $^{2}$. \\ Lucilla Poston ${ }^{2}$
}

Published online: 3 June 2020

(c) Springer Science+Business Media, LLC, part of Springer Nature 2020

\section{Correction to: Maternal and Child Health Journal https://doi.org/10.1007/s10995-020-02933-3}

The original version of this article contained an error in one of the author names. The co-author name was published as "Angela Flynn", instead it should be "Angela C. Flynn". The original article has been corrected.

Publisher's Note Springer Nature remains neutral with regard to jurisdictional claims in published maps and institutional affiliations.

The original article can be found online at https://doi.org/10.1007/ s10995-020-02933-3.

Claire A. Wilson

claire.wilson@kcl.ac.uk

1 Section of Women's Mental Health, Institute of Psychiatry,

Psychology and Neuroscience, King's College London and South London and Maudsley NHS Foundation Trust, PO31 King's College London, De Crespigny Park, London SE5 8AF, UK

2 Department of Women and Children's Health, King's College London, St Thomas' Hospital, 10th floor North Wing, London SE1 7EH, UK 